\title{
Vivenciando a outridade: escalas, indexicalidade e performances narrativas de universitários migrantes
}

\section{Experiencing Otherness: Scales, Indexicality and Narrative Performances of Migrant University Students}

Letícia Fonseca Richthofen de Freitas*

*Universidade Federal de Pelotas (UFPEL), Pelotas, Rio Grande do Sul / Brasil leticia.freitas@ufpel.edu.br

https://orcid.org/0000-0002-3544-7633

Luiz Paulo da Moita Lopes**

**Universidade Federal do Rio de Janeiro (UFRJ), Rio de Janeiro, Rio de Janeiro / Brasil moitalopes1@gmail.com

https:// orcid.org/0000-0002-3829-9824

RESUMO: Considerando a mobilidade dos signos e dos textos, o objetivo do artigo é analisar as performances narrativas construídas por três alunos de graduação que migraram para estudar. Isso é levado a efeito com base nos construtos teórico-analíticos de escala e de ordens de indexicalidade (BLOMMAERT, 2006, 2010; KELL, 2013; MELO; MOITA LOPES, 2014, 2015; SILVERSTEIN, 2003, 2009). O estudo aponta para os microfascismos presentes nas interações cotidianas, mas, sobretudo, para a possibilidade de, ao colocar o foco nas trajetórias de textos que se movem e que possibilitam, nesse fluxo, novas estruturas de participação nas escalas, identificar performances narrativas que desacomodam as visões estabelecidas de sociabilidade e de territorialização.

PALAVRAS-CHAVE: performances narrativas; textos; migração; microfascismos.

ABSTRACT: Considering the mobility of signs and texts, the aim of this article is to analyze the narrative performances of three university students who migrated to work on their undergraduate degrees. For this purpose, our research was based on theoretical concepts of scale and orders of indexicality (BLOMMAERT, 2006, 2010; KELL, 2013; MELO; MOITA LOPES, 2014, 2015; SILVERSTEIN, 2003, 2009). This study draws attention to microfascist attitudes detected in everyday interactions. By focusing on textual trajectories that make other structures of participation possible in the scaling projections, 
narrative performances that displace sedimented views of sociability and territorialization are identified.

KEYWORDS: narrative performances; texts; migration; microfascisms.

"Before there is anything like territory, there is movement."

"Antes que haja qualquer coisa parecida com território, há movimento."

(NAIL, 2015, p. 42)

Movimento e migração são temas recorrentes nos últimos anos em várias partes do mundo, sobretudo em razão da crescente onda de migrantes e de refugiados oriundos de guerras no oriente médio - Síria e Iraque -, de catástrofes como o terremoto e o furacão que atingiram o Haiti, ou devido a conflitos políticos e a condições econômicas desfavoráveis, como é o caso recente da Venezuela. Se a assim chamada crise migratória contemporânea, que tem gerado conflitos e fechado fronteiras, principalmente as de países europeus, parece um fenômeno recente na sua intensidade, há que se considerar que o migrante, ${ }^{2}$ em seus diversos aspectos, longe de ser uma exceção, sempre foi uma figura constitutiva de nossas sociedades (WESTMORELAND et al., 2016). Antes de pensarmos, então, na noção de território, temos de considerar o movimento, já que é a ideia de movimento que cria o território, sendo o movimento, por sua vez, inconcebível sem o processo de territorialização (NAIL, 2015).

Relacionado ao fenômeno da globalização (BAUMAN, 1999; BLOMMAERT, 2010; BLOMMAERT; RAMPTON, 2011), o processo que envolve o fluxo e a mobilidade não é recente, mas é novo em intensidade. Nesse sentido, Vertovec (2007) cunhou o termo "superdiversidade", justamente para dar conta do aumento do número de migrantes e de

\footnotetext{
${ }^{1}$ Todas as traduções são de responsabilidade dos autores do trabalho.

${ }^{2}$ Utilizaremos o termo "migrante" no artigo, entendendo e considerando sua relação com a questão do movimento, conforme sinaliza Nail (2015). No entanto, cabe deixar claro que há várias nuances para o termo, e há uma diferença significativa entre nomearmos "migrante" "o jovem desesperado que tenta viajar do Senegal para a França no trem de aterrissagem de um avião e o grande executivo de empresa transnacional que troca de residência dos Estados Unidos para o Japão, mantendo sua mobilidade quase cotidiana pela primeira classe das grandes companhias aéreas mundiais" (HAESBAERT, 2004, p. 250).
} 
suas características socioculturais, inclusive no mundo digital, em que os migrantes não saem de suas casas (BLOMMAERT; RAMPTON, 2011; MOITA LOPES, 2018).

Este artigo, contudo, se debruça sobre um tipo de migração que não se configura de maneira tão radical no que diz respeito à expulsão de determinado território ou à subjugação, mas constitui um importante fenômeno no que tange à construção de novos modos de sociabilidade e de territorialização: trata-se de algo relativamente recente no Brasil, qual seja, a migração de estudantes a diferentes regiões do país a fim de cursar o ensino superior em universidades públicas. Tal fenômeno deve-se, sobretudo, ao Sistema de Seleção Unificada (SiSU), que possibilita ao estudante, com base em sua nota do Exame Nacional do Ensino Médio (Enem), candidatar-se a uma vaga em quaisquer instituições federais de ensino superior (Ifes) que tenham aderido ao Sistema. Sublinhamos a relevância de estudar tal fenômeno, que tem ocorrido de maneira cada vez mais intensa e envolvido um número bastante expressivo de universitários que, ao se deslocarem, possibilitam a si e às pessoas do local para onde migraram experiências que desacomodam os modos estabelecidos de sociabilidade e de territorialização.

Ainda que pouco estudadas (ver, contudo, FREITAS, 2017; FREITAS; MOITA LOPES, 2017), tais experiências constituem, neste trabalho, um locus rico de investigação, uma vez que têm possibilitado a aproximação a performatividades diferenciadas sobre quem somos, que desconstroem a noção essencializada de nação como comunidade imaginada (ANDERSON, 2005) ou até mesmo de regionalidade, como aqui se verá. Um tal fenômeno precisa ser estudado para tornar visível a intolerância da parte daqueles que, orientados por tal noção de comunidade imaginada, produzem efeitos de sentidos que fazem sofrer. Viver entre aqueles que julgamos iguais é, minimamente, empobrecedor da vida humana, notadamente em tempos nos quais nos situamos cada vez mais em meio à multidão (HARDT; NEGRI, 2005), o que por sua vez pode levar aos pequenos ou grandes fascismos cotidianos daqueles que ainda persistem em se escorar e sobreviver em suas vidas locais.

Nesse sentido, cabe diferenciar aqui dois conceitos que se relacionam, mas operam de maneira diferente: fascismo e microfascismo. De acordo com Safatle (2017), o fascismo se caracteriza por três aspectos básicos: o primeiro deles abrange a violência de Estado e as práticas autoritárias de governo, calcadas sobretudo na busca de uma suposta ordem; o segundo 
aspecto refere-se ao desprezo por certos grupos minoritários, grupos esses que variam dependendo do contexto histórico. A terceira característica engloba todo tipo de essencialismo, no sentido de tentar construir uma coesão baseada em pertencimento identitário e na consequente defesa de fronteiras ou de um território, seja ele referente à nação, à regionalidade, à classe social, ao gênero, à sexualidade, à raça, à religião etc. Percebemos, no mundo de fluxos e de migrações em que vivemos, uma exacerbação dessa última característica do fascismo, provocada exatamente por tal mobilidade.

$\mathrm{Na}$ esteira do conceito de fascismo, Boaventura Sousa Santos (2016) cunhou o conceito de "fascismo social", a fim de dar conta de um tipo de fascismo que difere do fascismo político e surge no contexto de novas formas de exploração e de dominação (COSTA, 2017; MENDES, 2013). De acordo com Mendes, o fascismo social "caracteriza-se pela crise do contrato social, ou seja, pela ideia de que noções como as de igualdade, justiça, solidariedade e de universalidade deixam de ter valor”. Santos (2016) argumenta que, em democracias de baixa ou de baixíssima intensidade, como as que vivemos, experimentamos regimes sociais fascistas. As situações de fascismo social se caracterizam por um maior ou menor grau de violência, mas consistem sempre em situações na quais as vítimas são cidadãos que não possuem chance de recorrer a seus direitos fundamentais, uma vez que sua condição de cidadão se dá somente em nível formal, já que "as vítimas de fascismo social não são consideradas plenamente humanas por quem impunemente as pode agredir ou explorar" (SANTOS, 2016, p. 8).

Os microfascismos, por sua vez, embora estejam atrelados à noção de fascismo político e social, operam em um nível microssocial, como

práticas de exceção que concernem ao âmbito do micropolítico, práticas que habitam nossos pensamentos, nossas atitudes, nossos corpos. Que se infiltram por toda vida, não mais somente em um nível totalitário, definido, macro e visível, mas no entre, na invisibilidade, nas pequenas ações cotidianas (FONSECA et al., 2008, p. 40).

Nesse sentido, tais práticas de exceção, que atuam em nível micropolítico - e microssocial-, envolvem a exacerbação e a cristalização de preconceitos ou de discursos de ódio (BUTLER, 1997), que operam no dia a dia e fazem sofrer, com base em essencialismos sobre os outros. Podem agir, por exemplo, em relação à origem geográfica das pessoas, estigmatizando e fomentando ódio a alguém por ser oriundo de uma determinada região, 
província, cidade ou nação geralmente construída discursivamente como "atrasada", subdesenvolvida, menos civilizada, habitada por pessoas consideradas “inferiores” (ALBUQUERQUE JUNIOR, 2007).

Nosso objetivo aqui é analisar justamente nas narrativas de três estudantes os microfascismos cotidianos (i.e., no aqui e agora), engendrados nas narrativas que contam sobre suas vidas, que os aprisionam à sua origem geográfica/territorial em tempos intensos de translocalização (PENNYCOOK, 2007). Mais especificamente, serão analisadas as performances narrativas construídas pelos entrevistados, com base nos conceitos de escala e de ordens de indexicalidade (BLOMMAERT, 2006; 2010; KELL, 2013; MELO; MOITA LOPES, 2014, 2015; SILVERSTEIN, 2003, 2009). Entendemos que a experiência da migração confronta tanto o migrante como quem com ele convive, com situações que os desestabilizam, proporcionando, de alguma forma, a desconstrução de sentidos sedimentados que envolvem toda gama de intolerância e de atitudes microfascistas em relação ao outro. Tal desconstrução deveria ser celebrada como um movimento único de ir ao encontro da humanidade, como afirma Milton Santos (2000), ao defender uma outra globalização, adversa àquela do rentismo desenfreado que vivemos. Dessa forma, ressaltamos a importância de estudar como acontecem esses conflitos e esses reposicionamentos nas performances narrativas cotidianas desses sujeitos envolvidos nos processos migratórios.

\section{Escalas, indexicalidades e narrativas como performance: articulações teóricas}

Frente a esse ambiente superdiverso da contemporaneidade, é imprescindível que se estabeleçam outros modos de fazer pesquisa no campo de estudos da linguagem, que levem em conta justamente a necessidade de outras categorias de análise e de outra metalinguagem para dar conta de um mundo em constante fluxo (BLOMMAERT, 2006, 2010; BLOMMAERT; RAMPTON, 2011; JACQUEMET, 2005; MOITA LOPES, 2006, 2013, 2018; RAMPTON, 2006). É necessário então pensar sobre como dar conta da mobilidade do signo, considerando que ele não é puramente referencial, mas sim indexical, ou seja, o signo sempre aponta para o movimento dinâmico do significado na sócio-história, ou seja, para os discursos que indexicaliza em sua mobilidade. Tal característica implica a imprevisibilidade, a desigualdade e a assimetria na construção da vida social, envolvendo a circulação do signo, que toma uma dimensão singular no mundo de fluxos 
humanos, linguísticos e textuais em que nos situamos. Essa perspectiva envolve a diferença crucial entre estudos linguísticos representacionalistas e estruturalistas e aqueles indexicais.

Para entender o processo de construção de significados na interação humana atualmente, Blommaert (2006) e Kell (2013), entre outros, propõem o conceito de escala, considerado um instrumento analítico útil, já que por meio dele os sujeitos ordenam suas semiotizações do mundo social e material (BLOMMAERT; WESTINEN; LEPPÄNEN, 2014) ou perspectivizam o mundo social (CARR; LEMPERT, 2016). Escala é uma ferramenta produtiva, uma vez que entendemos que as pessoas e os textos se movem de maneira singular no mundo globalizado em que vivemos, e tal mobilidade se dá em espaços preenchidos por normas, códigos e expectativas. A escala é uma metáfora usada para descrever e compreender esses movimentos (BLOMMAERT, 2010). Sendo assim, os fenômenos e os eventos sociais, incluindo-se os linguísticos e de comunicação, se desenvolvem em um continuum de escalas e camadas: transitam do específico para o geral, do individual para o coletivo, do situado temporalmente para o transtemporal de forma intensa em nosso mundo de fluxos (BLOMMAERT, 2006). Cabe considerar ainda, ao se levar em conta a metáfora da escala, que os fenômenos sociais ocorrem concomitantemente no tempo e no espaço: eles se desenvolvem, dessa forma, no TempoEspaço, um TempoEspaço semiotizado - que é social, político, histórico, cultural e ideológico. ${ }^{3}$

Nas interações sociais, podemos perceber os movimentos de TempoEspaço por meio dos "saltos" ou transições de uma escala a outra, e tais saltos indexam a ordem social. Um exemplo bastante simples a que recorremos para explicar os saltos escalares diz respeito ao uso, por médicos e advogados, em uma dada situação de interação, de uma linguagem médica e jurídica específica: tal uso indexa um salto escalar ao qual, na maioria das vezes, o paciente ou o cliente não tem acesso, uma vez que "saltar escalas depende do acesso a recursos discursivos que indexam e iconizam determinados níveis de escala, e tal acesso é objeto de desigualdade" (BLOMMAERT, 2006, p. 6) ou de exercício de poder (FOUCAULT, 2010).

\footnotetext{
${ }^{3}$ Lembramos aqui o conceito de "cronotopo", desenvolvido por Bakhtin, que trata justamente da conexão entre tempo e espaço no âmbito literário. Para Bakhtin, cronotopo é a unidade indissociável entre tempo e espaço (AMORIM, 2006). O conceito de cronotopo tem sido recuperado na sociolinguística da mobilidade (conforme BLOMMAERT; DE FINA, 2015).
} 
Em relação ao conceito de escalas, é necessário acrescentar ainda que a conexão existente entre os níveis escalares é indexical, ou seja, "reside nas formas por meio das quais instâncias únicas de comunicação passam a ser capturadas, indexicalmente, como comunicação enquadrada, compreensível, como indicação de normas, gêneros, tradições, expectativas ordenadas social e culturalmente - fenômenos de um nível de escala superior" (BLOMMAERT, 2006, p. 4). Com base nesse argumento, podemos considerar que os significados são mediados e, nos processos de criação de significados, temos de considerar o entrelaçamento entre o enunciado com certas categorias mais amplas. Esse entrelaçamento se baseia na ideia de que certos "signos (não somente os linguísticos) 'indexam', ou apontam para alguma coisa que é externa a eles (DE FINA; GEORGAKOPOULOU, 2012, p. 176) e para as condições circundantes em que são usados (SILVERSTEIN, 2009). Segundo Silverstein (2009, p. 756), a indexicalidade "é o princípio de contextualização dos signos linguísticos em uso", ou seja, a indexicalidade é evidenciada pela maneira como os signos apontam, para os interlocutores, os discursos mobilizados na interação. Dessa forma, nas nossas interações locais e situadas, os significados produzidos localmente estão sempre imbricados em significados produzidos em nível macrossocial. ${ }^{4}$ Entendemos, portanto, que é a fricção entre esses dois níveis que dá conta dos processos de construção do significado, assim como da possibilidade de significados inovadores (FABRÍCIO; MOITA LOPES, no prelo), como veremos ao concluir.

Complementando essa ideia, Blommaert (2006, 2010) sublinha que a indexicalidade é ordenada de duas maneiras: a primeira, conforme indica Silverstein (2003), diz respeito à ordem indexical, que considera o fato de os significados indexicais ocorrerem de modo a possibilitar padrões de semelhança e de estabilidade levando em conta padrões compartilhados de significados e tradições anteriores de fazer sentido. A capacidade de atingir a compreensão na comunicação seria a capacidade de relacionar

\footnotetext{
${ }^{4}$ Nesse sentido, Blommaert (2006, p. 3) lembra que "essa dualidade em que a língua ocorre tanto como fenômeno individual, único, e de uma só época quanto simultaneamente como fenômeno coletivo e relativamente estável, foi frequentemente capturada sob rótulos como 'micro' e ‘macro"' - o que pode ser comparado com a distinção que Gee (2004) faz entre Discurso, em maiúsculo, que faz alusão ao conhecimento, às ideologias e a maneiras de estar no mundo, em um nível macrossocial, e discurso, em minúsculo, que diz respeito à linguagem em uso, em nível microssocial.
} 
os significados produzidos em interações momentâneas com aqueles disponíveis em instâncias anteriores de produção de sentido.

O segundo tipo de ordenação é chamado de ordens de indexicalidade, que "opera em um plano superior de estruturação social", apontando para aspectos cruciais de hierarquia, poder e de desigualdade no domínio da semiose (BLOMMAERT, 2010, p. 37). Nesse ponto, chamamos atenção justamente para a questão das assimetrias e das relações de poder que atravessam a noção de ordens de indexicalidade, ${ }^{5}$ e de como tal questão é crucial para as análises realizadas. Conforme indica Blommaert (2010, p. 37), "se formas de semiose são valorizadas social e culturalmente, esses processos de avaliação devem apresentar vestígios de poder e autoridade, de lutas em que houve vencedores e perdedores e, em geral, o grupo de vencedores é menor que o de perdedores". Assim, ainda segundo Blommaert (2010), as ordens de indexicalidade indicam as hierarquias de determinados valores para certos grupos em um TempoEspaço.

Outra ferramenta teórico-analítica neste trabalho é a narrativa (CONNELLY; CLANDININ, 2011; FREEMAN, 2013; KIM, 2016; GUBRIUM; HOLSTEIN, 2003; SQUIRE et al., 2014), entendida como uma prática discursivo-interacional social e situada (BASTOS; BIAR, 2015; MOITA LOPES, 2009). Assim, há que se levar em conta o caráter performativo das narrativas, uma vez que o ato de narrar é ação, é performance, e é nesse ato que construímos os significados sobre quem somos, sobre quem são os outros e sobre o mundo (KIM, 2016; MOITA LOPES, 2009; PETERSON; LANGELLIER, 2006). Sendo assim, para dar sentido às nossas experiências, estamos sempre construindo significados interacionalmente no aqui e no agora (i.e., microssocialmente) - em performances narrativas.

Cabe ressaltar, entretanto, que com a mobilidade e a fluidez a questão da situacionalidade adquire outra dimensão: ela só faz sentido, na mobilidade, quando a consideramos como o momento de um continuum ou, segundo argumenta Kell (2013, p. 20), como “momentos na pontuação da semiose,

\footnotetext{
${ }^{5}$ Blommaert (2010) deixa claro que o conceito de ordens de indexicalidade é inspirado no conceito de ordem do discurso, de Foucault (1999). Foucault se debruça sobre a emergência de determinadas regras de produção do discurso, sempre atravessadas por relações de poder. De acordo com Foucault, "o discurso não é simplesmente aquilo que traduz as lutas ou sistemas de dominação, mas aquilo por que, pelo que se luta, o poder do qual nos queremos apoderar" (1999, p. 10).
} 
momentos em que o significado é suficientemente 'fixo' para que ele seja transportado e projetado para outros contextos". Dessa forma, ao levarmos em conta a situacionalidade das narrativas, é necessário atentarmos para o fato de que, antes que haja narrativa situada, há movimento de textos e de seus significados, que são então entextualizados em performances narrativas, “momentos na pontuação da semiose" (KELL, 2013), como já citado.

\section{Contexto e metodologia}

Com base no entendimento de que as pessoas se utilizam de diversos recursos semióticos para produzir sentidos através dos contextos, argumentamos que, quando as narrativas produzidas pelos universitários se movem, as indexicalizações provavelmente são outras. Nesse fluxo de textos e de significados, a situação de interação - ou, como propõe Kell (2013), os espaços-eventos - constitui aquele ponto de fixidez, mesmo que fugaz, em que os sentidos são produzidos e podem ser transportados e projetados. A prática situada consiste em um recurso metodológico que fixa o fio semântico (KELL, 2013). Esses espaços-eventos constituem aqueles momentos em que os atores sociais tentam "alcançar propósitos e fazem as coisas acontecerem projetando significados em espaços-eventos posteriores com diferentes estruturas de participação" (KELL, 2013, p. 9). Ou seja, levando-se em conta os processos de contextualização que ocorrem nas trajetórias textuais, é possível analisar de que maneira as estruturas de participação ${ }^{6}$ dos atores sociais, ao agirem e tentarem "fazer as coisas acontecerem", se modificam. O foco, então, deve ser colocado no processo de contextualização, não tomando o contexto como algo pré-dado e formatado, e deve-se tomar o contexto discursivo-interacional como crucial para a compreensão dos sentidos produzidos naquele momento, sendo o evento narrativo tão importante quanto o evento narrado ${ }^{7}$ (BAUMAN, 1986).

Para analisarmos os movimentos nas escalas, nesse processo de contextualização, nos debruçamos, então, nas mudanças da estrutura de

\footnotetext{
${ }^{6}$ Evocamos Philips (2002), que considera, na análise da conversa, como certos traços da estrutura interacional produzem um sistema de organização da interação.

${ }^{7}$ Segundo Bauman (1986), evento narrado diz respeito à história contada no momento da interação; já evento narrativo se refere à performance narrativa que ocorre entre narrador e audiência no momento da interação.
} 
participação dos envolvidos naqueles espaços-eventos analisados. Autores como Kell (2013), Carr e Lempert (2016), Gal (2016) e Irvine (2016) chamam a atenção, de diferentes formas, para a necessidade de compreender os processos de escalabilidade ou de projeções de escalas, considerando que a vida social ocorre em várias dimensões. Sendo assim, ao analisar os processos de escalabilidade, é preciso levar em conta que as escalas não ocorrem só verticalmente - em nível hierárquico -, mas também, como propõe Kell, horizontalmente.

A análise será conduzida com base em uma entrevista narrativa gerada em um ambiente acadêmico, em um evento narrativo do qual participaram, ao mesmo tempo, três estudantes - Bárbara, João e Antônio - e um dos pesquisadores, que deu aula aos universitários e comentou sobre a pesquisa, solicitando colaboradores. Bárbara tinha 22 anos na época em que ocorreu a entrevista narrativa e é do estado do Rio de Janeiro; João, com 22 anos na época, e Antônio, 26, são do estado de São Paulo. Bárbara e João frequentavam o mesmo curso, e Antônio, outro, mas na mesma faculdade. Os três estudantes se disponibilizaram a participar e, antes da gravação, todos os detalhes da pesquisa foram esclarecidos e explicados. Diante da ciência e da concordância dos três, foi assinado, por cada um deles, um termo de consentimento livre e esclarecido. Os universitários, dois rapazes e uma moça, foram questionados se gostariam de escolher um pseudônimo. Como não sentiram necessidade de fazer isso, eles foram nomeados, de forma aleatória, como Bárbara, João e Antônio. O gravador então foi ligado e o evento narrativo transcorreu sem interrupções por aproximadamente $2 \mathrm{~h} 30$. Os três participaram de maneira equânime do evento narrativo, contando detalhadamente várias de suas experiências como universitários migrantes para o Rio Grande do Sul. Os trechos escolhidos para análise dizem respeito a um arcabouço topical ${ }^{8}$ que mobilizou bastante os estudantes durante a entrevista narrativa, qual seja, as tensões e os conflitos ocorridos devido à sua “origem geográfica e de lugar” (ALBUQUERQUE JUNIOR, 2007).

\footnotetext{
${ }^{8}$ Brown e Yule (1983) ressaltam que é mais adequado se referir a um arcabouço topical e contextual em vez de a uma noção de tópico como simplesmente "aquilo sobre o que se está falando". Dessa forma, tal arcabouço deve levar em conta aspectos como o tempo e o local onde o discurso foi proferido, saber quem proferiu o discurso e quem é a audiência, além de considerar traços contextuais como pessoas, locais, entidades, eventos e fatos que precedem a conversa.
} 
Para analisar as performances narrativas dos universitários, que mobilizam certas ordens de indexicalidade que transitam em diferentes escalas, vamos nos utilizar de alguns recursos indexicais. Mais especificamente, lançaremos mão das pistas indexicais ${ }^{9}$ propostas por Wortham (2001). De acordo com o autor, quando se narra, são utilizadas pistas linguísticas que referem (referência) e predicam (predicação) os personagens da narrativa, de forma a posicioná-los. Da mesma forma, o narrador usa descritores metapragmáticos - verbos discendi (de dizer) - para descrever ações de personagens e eventos por ele avaliados. A citação representa um evento de fala, combinando a referência a um personagem citado, o verbo metapragmático e a enunciação citada. Também constituem pistas linguísticas sobre o posicionamento os índices avaliativos, que associam os personagens a certas posições ou a grupos sociais por meio de suas falas e posicionam o narrador em relação a eles. A modalização epistêmica, por fim, diz respeito ao "status epistêmico da narração e dos eventos narrados". Tais pistas serão usadas então para compreender quais são as ordens de indexicalidade mobilizadas nessa situação de interação e como há mudanças na estrutura de participação nas performances narrativas dos estudantes ao haver modificação e alternância nas escalas.

\section{Experimentando a vida em outro TempoEspaço - análise das performances narrativas de três universitários}

Passaremos à análise de alguns trechos ${ }^{10}$ da entrevista narrativa de três universitários que migraram para estudar em uma universidade pública de uma cidade do Rio Grande do Sul. Todos os trechos escolhidos para análise envolvem um arcabouço topical de conflito e de desconforto no que tange à origem geográfica dos alunos. O primeiro excerto destacado diz respeito a um episódio ocorrido com João e Antônio em uma reunião entre alunos e professores:

\footnotetext{
${ }^{9}$ Wortham (2001) se baseou no conceito de pistas de contextualização de Gumperz (2002) para propor o conceito de pistas indexicais.

${ }^{10}$ A narrativa foi gravada e posteriormente transcrita. Assim como em Moita Lopes (2009), foram utilizadas as seguintes convenções para a transcrição: / para pausa curta; // para pausa longa; [] para comentário dos autores e [...] para omissão de texto.
} 


\section{Excerto 1:}

01 Antônio (A): Você comentou dos gafanhotos?

02 João (J): A gente tava numa reunião com os veteranos / foi a primeira vez que eu

03 conheci os representantes do grupo // tinha os veteranos e os professores / até que

04 caiu nesse assunto de retribuir com a cidade / e esse foi um assunto que me deixou

05 muito nervoso / porque eu já tava de saco cheio / isso foi o estopim / / segundo dia

06 aqui eu já tava assim e vem o cara fala assim / que a gente tinha que dá de volta à

07 cidade alguma coisa porque a cidade recebia a gente / porque a gente usufruía das

08 coisas da cidade porque a gente não paga imposto // usufruem das coisas da cidade

09 sem deixar nada e fazem que nem gafanhotos e vão embora.

10 Entrevistador (E): E ninguém falou nada?

11 J: mas na hora deu vontade / mas a coordenadora tava lá / ela concordou sabe //

12 esse que é o pior a gente vai falar é minoria / cê tá ali vai falar / fico quieto sabe

13 A: Sim cara / vem no primeiro contato comparar a gafanhoto

A metáfora utilizada na reunião para se referir àqueles alunos que são de fora - indexicalizada pelo item lexical "gafanhoto" - mobiliza uma ordem de indexicalidade que circula no TempoEspaço, em uma escala transtemporal, fazendo uma clara referência a narrativas bíblicas, nas quais o gafanhoto é considerado uma verdadeira praga, por chegar de repente, dizimar plantações e ir embora. Os alunos que vêm de fora são comparados a gafanhotos pois também chegariam de repente a um lugar, se apropriariam do que o local oferece - "usufruem das coisas da cidade sem deixar nada" (1. 09) - e iriam embora - "e fazem que nem gafanhotos e vão embora” (1. 09). 
A utilização do item lexical "a gente” posiciona e inclui João e Antônio ${ }^{11}$ no grupo de gafanhotos, demonstrando o status epistêmico privilegiado do narrador/personagem. Ademais, há um certo encadeamento de predicações para o referente "a gente" - o grupo dos que são de fora que reforça essa ordem de indexicalidade "quem é de fora se apropria e se beneficia". Isso é indexicalizado pelas pistas linguísticas "usufruir" - "a gente usufruía das coisas da cidade" (1.07 e 08); "usufruem das coisas da cidade" (1. 08) -, "receber" - "a cidade recebia a gente" [em oposição a como cidade é predicada] (1. 07) -, (não) "pagar" - "a gente não paga imposto" (1. 08) -, "deixar" - "sem deixar nada" (1.09), "fazer" - "fazem que nem gafanhotos" (1. 09) - e "ir embora" - "vão embora" (1. 09). Também se percebe o status epistêmico privilegiado de João pelos comentários no evento narrativo para se referir ao seu estado emocional em relação ao "assunto de retribuir com a cidade" (1. 04). Ele se autopredica pelos itens lexicais "muito nervoso" - "me deixou muito nervoso" (1. 04 e 05) - e "de saco cheio" - "eu já tava de saco cheio" (1. 05) - para descrever seu estado de espírito frente às cobranças de retribuição pelo que a cidade oferecia.

Além disso, no comentário de Antônio, na linha 15, fica subentendido que essa ordem de indexicalidade não é situada temporalmente somente na interação descrita no evento narrado - na reunião entre alunos e professores: ela é transtemporal no sentido de que retoma a metáfora bíblica da praga dos gafanhotos, mas também em relação ao fenômeno dos alunos migrantes naquele ambiente. Isso acontece porque, apesar de Antônio afirmar que eles são nomeados como gafanhotos no primeiro encontro - "vem no primeiro contato comparar a gafanhoto” (1. 13) -, para que tal afirmação por parte dos veteranos e dos professores tenha sido feita, pressupõe-se que já houve outros universitários migrantes que, na concepção deles, usufruíram da cidade e foram embora sem deixar nada, como gafanhotos. Ou seja, houve outros textos e outros significados em movimento que viajaram para esta narrativa e foram entextualizados nesse espaço-evento em um novo processo de contextualização que fixa momentaneamente o fio semântico.

Quando foram indagados se não questionaram o que havia sido dito, Antônio e João mobilizam outra ordem de indexicalidade "falta de legitimidade para protestar", sugerida também pelo item lexical "minoria",

\footnotetext{
${ }^{11}$ Bárbara estava presente no evento narrativo, mas não participou dos eventos narrados nos excertos 1, 2 e 3. Sua participação se dá em um excerto destacado nas considerações finais.
} 
que predica o referente "a gente": "a gente vai falar é minoria" (1. 12). Tal ordem de indexicalidade é mobilizada por uma transição escalar para baixo, o que explica o silenciamento dos alunos migrantes - "fico quieto sabe" (1. 12), já que, por serem minoria, seu discurso e sua voz não seriam ouvidos. Outro fator que gera esse movimento escalar para baixo é a presença de uma figura de poder, a coordenadora de curso - "mas a coordenadora tava lá" (1. 11), cuja postura de concordância com os discursos mobilizados naquela ordem de indexicalidade foi decisiva para que os alunos não reagissem e silenciassem diante daquela situação de exercício de poder microfascista na escala - "ela concordou sabe (1.11)". Temos aqui uma situação em que claramente percebemos os aspectos de hierarquia e de desigualdade no domínio da semiose, exercidos por essa figura de poder.

Um segundo excerto que destacamos também gira em torno de uma ordem de indexicalidade de preconceito contra a origem geográfica:

Excerto 2:

14 A: Teve muito problema / esses dias eu tava conversando com o marido da dona da

15 pensão e aí a gente já não tem um apreço muito grande por ele / eu e o $\mathrm{X} / /$

16 estávamos comendo na sala de jantar / e aí ele começou / nós estávamos conversando

17 sobre assuntos diversos e de repente ele começou a falar sobre política [...] aí chegou

18 num momento que ele falou assim "não a única coisa que nordestino serve é pra ser

19 vagabundo e votar no PT" // nesse momento o X / ele levantou da mesa e saiu / e

20 peguei levantei e falei oh não é assim / / aí eu peguei e falei assim pra ele // eu vou

21 colocar a seguinte hipótese / vamos supor que eu tenho o mesmo tipo de pensamento

22 que você de achar que o meu estado é superior ao de alguém / / eu poderia usar aqui

23 que o meu estado é mais industrializado / ou que tem as maiores fábricas / as maiores 
24 empresas do país / e começar a usar esses argumentos com você / e falar que aqui no

$25 \mathrm{sul} /$ pela maneira que vocês conseguem lidar com a economia / tem muito mais gado

26 são maneiras diferentes / assim como o nordeste é muito forte o turismo e as pessoas

27 veem isso como coisa de vagabundo / e o que você sentiria? // e ele falou "mas seria

28 injusto" / / aí eu peguei e falei imagina se eu fosse um nordestino / "ah mas você não

29 é / é de São Paulo" / / eu disse eu sou de São Paulo mas é por isso que não posso me

30 incomodar com esse posicionamento? / / e aí a gente começou a discutir e aí eu

31 comecei a apontar todos os erros e porquês / ele não falou nenhum argumento que

32 preste / começou a se desculpar na hora que ele viu que eu não gostei do que ele

33 falou.

Nesse excerto, Antônio narra um conflito entre ele e o marido da dona da pensão em que um amigo dele, denominado X, morava. Embora o assunto que tenha gerado o conflito fosse política - "e de repente ele começou a falar sobre política" (1. 17) -, logo é mobilizada a ordem de indexicalidade "preconceito contra origem geográfica": ao tratar sobre política, o marido da dona da pensão se refere aos nordestinos como vagabundos e como eleitores do Partido dos Trabalhadores (PT) ${ }^{12}$ - "não a única coisa que nordestino serve é pra ser vagabundo e votar no PT" (1. 18/19). O paralelismo com que a predicação aos nordestinos é feita coloca no mesmo campo semântico alguém ser vagabundo e votar no P'T; além disso, essa afirmação é reforçada pelo emprego da pista indexical "servir", intensificado pelo item indexical avaliativo "única”, isto é, os nordestinos não

\footnotetext{
${ }^{12}$ A entrevista foi gerada em 2014, ano em que Dilma Rousseff foi reeleita. Na época circularam alguns discursos preconceituosos nas redes sociais, que creditavam sua eleição sobretudo aos votos recebidos de eleitores da região Nordeste do Brasil. Esses discursos preconceituosos vinculavam o voto dessas pessoas à falta de conhecimento e à ignorância.
} 
servem para mais nada, só para fazer coisas negativas como as explicitadas pelo interlocutor, no caso ser vagabundo e votar no PT, coisas que, na afirmação em questão, se equivalem.

Cabe ressaltar ainda que o referente "nordestino", nesse caso, evoca uma ordem de indexicalidade associada à preguiça, ao subdesenvolvimento, à pobreza, entre outras predicações (ALBUQUERQUE JUNIOR, 1999; FREITAS, 2006; SILVA, 2012). Como não se pode separar linguagem de prática social, "nordestino" aqui indexicaliza não só um fenômeno linguístico, mas discursivo, portanto, um fenômeno social, político, cultural e ideológico, desenvolvido em uma ordem escalar que transita no TempoEspaço semiotizado, cujos rastros textuais recuperam e reatualizam, nesse fio discursivo, a ideia de que nordestino seria vagabundo.

Antônio, no entanto, se contrapõe a esta ordem, posicionando-se de forma enfática, argumentando contra o que foi dito - "e peguei levantei e falei oh não é assim" (1. 20). O argumento de Antônio é desenvolvido propositalmente na mesma ordem de indexicalidade de preconceito, o que é indexicalizado pelos descritores metapragmáticos "supor" e "achar", e ao predicar o referente "estado" como "superior" - "vamos supor que eu tenho o mesmo tipo de pensamento que você de achar que o meu estado é superior ao de alguém" (1.21/22). Ao fazer isso, Antônio então predica o seu estado, São Paulo, como "mais industrializado" - "eu poderia usar aqui que o meu estado é mais industrializado" (1.23) -, como o "que tem as maiores fábricas" - "ou que tem as maiores fábricas" (1. 23) e como o que tem as "as maiores empresas do país” (1. 23/24).

Nesse ponto há uma mudança clara na estrutura de participação de Antônio e, consequentemente, uma modificação no nível escalar: o dono da pensão, ao fazer o comentário, opera em um nível escalar horizontal, em que as diferenças hierárquicas são abrandadas; ele se coloca no mesmo nível de Antônio. O universitário, no entanto, modifica sua estrutura de participação, provocando uma mudança no nível escalar, que passa a ser vertical: ao predicar o seu estado como o mais industrializado e ao discorrer sobre a base da economia do Rio Grande do Sul - "e falar que aqui no sul / pela maneira que vocês conseguem lidar com a economia / tem muito mais gado" (1. 24/25) e do Nordeste - "assim como o nordeste é muito forte o turismo e as pessoas veem isso como coisa de vagabundo" (1. 26/27). Ele se posiciona então como alguém que tem conhecimento, informação e consequentemente legitimidade para argumentar contra aquilo que havia 
sido dito. A performance narrativa de Antônio o coloca em um nível superior na escala, o que possibilita que ele aja como alguém que pode questionar diretamente seu interlocutor, fazendo com que ele se coloque no lugar do outro - "e o que você sentiria?" (1. 27) -, o que gera uma resposta enfática: "e ele falou 'mas seria injusto"' (1. 27/28).

A mudança de nível escalar e de estrutura de participação é indexicalizada, na sequência, pelos descritores metapragmáticos "discutir" e "apontar" e pelos itens lexicais "erros e porquês" - "e aí a gente começou a discutir e aí eu comecei a apontar todos os erros e porquês" (1. 30/31) e pela avaliação expressa então pelo interlocutor, que, por não ter argumentos plausíveis e suficientes - "ele não falou nenhum argumento que preste" (1. 31/32) -, se desculpa: "começou a se desculpar na hora que ele viu que eu não gostei do que ele falou" (1. 32/33). Ao utilizar argumentos ligados à economia e ao demonstrar relativo conhecimento sobre o que estava defendendo, Antônio transita escalarmente do específico para o geral e do individual para o coletivo, o que lhe confere legitimidade e lhe permite saltar escalas e reposicionar seu interlocutor, a quem só resta se desculpar.

Dando continuidade à análise da performance narrativa, foi selecionado mais um trecho em que a questão do preconceito sobre a origem geográfica aparece, agora sob outra perspectiva:

Excerto 3:

33 A: Lembrei daquele dia que a gente foi pro supermercado / era época de jogo da

34 Copa do Mundo / / só que o Brasil já tinha perdido foi a final / e aí nós entramos /

35 chegou um cara um dos funcionários daí ele foi e falou "tá triste por que o Brasil tá

36 perdendo" [...] e ela [uma funcionária do supermercado] falou: "eu não tenho por que

37 ficar triste eu não sou brasileira eu sou gaúcha" //e aí nós ouvimos isso e pra gente

38 essa postura é muito engraçada. [...]

$39 \mathrm{~J}$ : Assim / / eu tive bastante atrito com isso / eu participava de um grupo de estudos

40 na faculdade de X / e tinha um povo lá principalmente um cara que ele é muito / 
41 muito desse orgulho tradicionalista / ele colocava a capa da bandeira do Rio Grande

42 do Sul / essas coisas / e não era só orgulho de ser gaúcho / ele era orgulho de não ser

43 brasileiro sabe // diferente / ele é agressivo / e eu via que ele falava comigo em tom

44 de escárnio falava como se eu fosse inferior toda vez que eu ia conversar com ele

45 sabe / ah tu é paulista sabe.

No excerto 3, os trechos destacados giram em torno de duas ordens de indexicalidade que se complementam, quais sejam, o "orgulho nacional/ regional" e a "xenofobia". Tanto Antônio quanto José narram episódios em que dois personagens - a funcionária de um supermercado e um colega de faculdade - se comportam de maneira orgulhosa por serem gaúchos: "eu não sou brasileira eu sou gaúcha" (1.37) e "não era só orgulho de ser gaúcho / ele era orgulho de não ser brasileiro sabe” (1. 42/43).

No primeiro caso, o narrador Antônio se utiliza de uma citação da fala da funcionária do supermercado a fim de ressaltar a maneira como ela se autodenomina, por meio da predicação "(não ser) brasileira, (ser) gaúcha" - "eu não sou brasileira eu sou gaúcha” (1. 37). Mesmo que não tenha participado ativamente desse evento narrado, ao utilizar os índices avaliativos "muito engraçada" para predicar a postura da funcionária - "pra gente essa postura é muito engraçada" (1. 37/38) -, Antônio se posiciona em um nível horizontal de escala, pois os índices avaliativos utilizados na predicação - "muito engraçada" - de certa forma desconstroem o discurso dela em relação à sua suposta superioridade por ser gaúcha e não brasileira. Note-se que a funcionária se coloca em um nível vertical na escala, e esse nível hierárquico é desconstruído por Antônio quando ele se posiciona no evento narrado; tal atitude de Antônio corrobora o argumento de autores como Irvine (2016, p. 215), de que não se pode partir de uma versão pronta de escala, uma vez que a vida social não ocorre "em uma única dimensão de grandeza (ou pequenez)".

No segundo caso, temos essa primeira ordem de indexicalidade do orgulho nacional/regional atrelada à segunda ordem mencionada, a de "xenofobia". Essa última ordem é mobilizada a partir do momento em que José narra as características do colega, predicado como agressivo - "ele é 
agressivo" (1. 43) - e, sobretudo, o modo como ele se comporta em relação ao narrador. Isso é indexicalizado pelo descritor metapragmático "falava", em "tom de escárnio", e pelas pistas avaliativas "como se fosse inferior": "e eu via que ele falava comigo em tom de escárnio falava como se eu fosse inferior toda vez que eu ia conversar com ele sabe" (1. 43/44/45).

José é enfático ao avaliar o ocorrido, já que, ao contrário de Antônio, ele não avalia esse tipo de performance como algo engraçado. Ele se utiliza dos índices avaliativos "bastante atrito" para julgar a situação: "eu tive bastante atrito com isso" (1. 39). Ele avalia a situação e questiona a forma como o interlocutor do evento narrado, no caso o colega mencionado, se posiciona, assumindo uma estrutura de participação que também movimenta a escala em nível horizontal, a partir do momento em que nega a posição de superioridade na qual o interlocutor se coloca.

Essa negação acontece, primeiramente, quando ele, por meio da modalização epistêmica, informa à entrevistadora o que se passa com o colega: ele não tinha só orgulho por ser gaúcho, ele tinha orgulho por não ser brasileiro - "e não era só orgulho de ser gaúcho / ele era orgulho de não ser brasileiro sabe” (1. 42/43). Ao fazer esse comentário, José, além de demonstrar um status epistêmico privilegiado, deixa transparecer o quão absurdo é a performance do colega. Tal negação também se dá, em segundo lugar, pelo uso do descritor metapragmático "falava" - "e eu via que ele falava comigo em tom de escárnio" (1. 43/44) - e da predicação "inferior" - "falava como se eu fosse inferior" (1. 44). O uso dessas pistas linguísticas desconstrói e desqualifica a performance do colega, uma vez que José deixa clara sua discordância.

É importante salientar que esse movimento horizontal no nível escalar é possível pelo fato de, entre os envolvidos, nenhum deles ocupar posições institucionais de poder, ao contrário do que ocorreu no episódio narrado no excerto 1, em que havia a presença da coordenadora do curso, o que tornou quase impossível o movimento de horizontalidade na escala e a mudança na estrutura de participação. Nesse último caso, o movimento escalar é vertical, demonstrando a hierarquia entre os participantes, o que inviabilizou mudanças na estrutura de participação e a consequente impossibilidade de se saltar escalas.

Cabe mencionar ainda que, nos dois casos, o item lexical gaúcho/a serve como atributo do que pode ser chamado de "nacionalidade", mesmo sendo uma predicação relativa à origem regional, corroborando o que 
foi argumentado em Freitas (2007), no sentido de que, em alguns casos, o discurso do gauchismo constrói, mais do que uma ideia de identidade regional, uma ideia de identidade nacional, construindo, de certa forma, uma espécie de nação gaúcha, o que mobiliza a ordem de indexicalidade do "orgulho nacional". Os discursos nacionalistas, ao desqualificarem e atribuírem características negativas a quem é de fora, são uma das principais formas de se posicionar e de posicionar os outros de maneira preconceituosa no exercício de microfascismos.

Conforme nos lembra Albuquerque Junior (2007, p. 21), "muitos dos preconceitos quanto à origem geográfica advieram do discurso nacionalista", e isso pode ser notado pelo modo como as duas ordens de indexicalidade mencionadas - orgulho nacional/regional e xenofobia - se complementam, isto é, temos um discurso nacionalista (ainda que regional) que fomenta os microfascismos em relação à origem geográfica de José. Tais discursos são mobilizados nessas ordens de indexicalidade, transitando em escalas que transcendem, local e temporalmente, as situações de interação narradas, já que tais discursos microfascistas se movem no TempoEspaço sob diversas perspectivas, como temos assistido recorrentemente no mundo de intensos fluxos migratórios e do ambiente superdiverso em que, em maior ou menor grau, vivemos.

\section{Fechando o percurso - a vida entre os microfascismos cotidianos}

Como já foi dito, o mundo em que vivemos é constituído pela mobilidade, em dimensões talvez nunca experimentadas antes: fluxo não só de pessoas, mas também de textos, o que gera possibilidades imensas de construção de novos modos de dar sentido a ele e a nós mesmos. Entretanto, frente à oportunidade de construção de novos modos de sociabilidade, nos vemos cada vez mais diante de maneiras cristalizadas de se comportar e de entender o mundo, que podem gerar atitudes autoritárias e microfascistas na vida cotidiana, como vimos ao analisar as narrativas dos universitários em questão.

Os três excertos destacados permitem vislumbrar maneiras distintas de viver a outridade como migrante. Todas elas confrontam os universitários com situações desestabilizadoras no que tange aos microfascismos que circulam e se estabelecem nas relações cotidianas: seja a surpresa e a perplexidade por terem sido comparados a gafanhotos sem conseguir esboçar reação, seja a percepção, no caso de José, de ser tratado pelo 
colega como inferior pelo fato de ser paulista. Essas são situações pontuais vivenciadas pelos estudantes em questão, mas são situações que muito provavelmente se repetem com outras roupagens Brasil afora, uma vez que os textos se movem, produzindo, na sua trajetória, em pontos específicos da semiose, novos sentidos em novas escalas.

Tomamos esses discursos microfascistas como "enunciações mântricas", que, ao viajarem e se repetirem, podem se modificar e adquirir novos sentidos, subvertendo, muitas vezes, os sentidos sedimentados. Conforme assinala Brah, "os mantras são feitos para serem repetidos precisamente porque se espera que de cada ato repetitivo surjam novos significados. A enunciação mântrica é um ato de transformação, não de ossificação" (BRAH, 2011, p. 37-38). Nesse sentido, salientamos aqui a esperança de que a performatividade da linguagem (AUSTIN, 1990; BUTLER, 2003; PENNYCOOK, 2007) venha gerar recriação de significados inovadores em cada nova interação, que venham desmantelar os microfascismos tratados aqui.

Chamamos atenção para a relevância de estudar essas interações cotidianas, colocando o foco nessas trajetórias de textos que se movem e vão construindo, nesse fluxo, novos arcabouços de participação nas escalas. Nesse sentido, o construto da escala nos permite olhar com mais fluidez para os fenômenos que ocorrem na vida social, pois conforme nos lembram Carr e Lempert (2016, p. 21), "o estudo da escala requer uma abertura, uma sensibilidade pragmática que nos permita descobrir e narrar, em vez de captar e catalogar as diversas formas de a vida social ser projetada em escalas".

Argumentamos que a experiência desses universitários que migram para estudar pode ser uma maneira de transformação desses significados que adquirem uma aparência de substância (BUTLER, 2003), como foi possível perceber na interação entre Antônio e o marido da dona da pensão: após as considerações de Antônio, ele aparentemente reviu sua posição e acabou se desculpando, mobilizando outra ordem de indexicalidade e modificando as estruturas de participação na escala. Além disso, como pontua Bárbara no final da entrevista narrativa, talvez a falta de contato com o outro faça com que algumas pessoas não alcancem a dimensão de como o discurso microfascista pode ferir (SILVA, 2012): "muitas vezes as pessoas não fazem por mal / porque elas foram criadas assim / / pela falta de contato com 
coisas diferentes / elas não sabem o quanto pesam no outro / porque pra ele pro cara que falou mal do nordestino talvez não pese".

Embora não se possa afirmar que só o contato com o outro seja suficiente para desconstruir discursos e atitudes microfascistas, de preconceito, de intolerância e de ódio, essa experiência de migração propiciada pelo SiSU é uma forma de minar, em um nível micro e horizontal das escalas, algumas dessas atitudes, tanto por parte de quem é do lugar quanto por parte dos universitários que migram. A experiência de viver a e de conviver com a outridade pode colocar sob suspeita determinadas ideias que são, muitas vezes, como afirma Antônio, repetidas sem pensar: "eu vejo que mudar pra cá no sentido de estudos no sentido de tudo de amadurecimento / de muita coisa / de quebrar um pouco das ideias que eu tinha que não eram minhas / foi graças a isso". Em um mundo de fluxos avassaladores de pessoas e de ideias, pensar na microfísica do poder (FOUCAULT, 2010) e da resistência pode ser uma saída para desconstruir tantos discursos fascistas, de preconceito, de ódio e de intolerância que vêm emergindo igualmente de maneira avassaladora.

\section{Referências}

ALBUQUERQUE JUNIOR, D. M. A invenção do Nordeste e outras artes. São Paulo: Cortez, 1999. 340 p.

ALBUQUERQUE JUNIOR, D. M. Preconceito quanto à origem geográfica e de lugar: as fronteiras da discórdia. São Paulo: Cortez, 2007. 135 p.

AMORIM, M. Cronotopo e exotopia. In: BRAIT, B. (Org.). Bakbtin: outros conceitos-chave. São Paulo: Contexto, 2006. p. 95-114.

ANDERSON, B. Comunidades imaginadas: reflexões sobre a origem e a expansão do nacionalismo. Lisboa: Edições 70, [1983] 2005. 350 p.

AUSTIN, J. L. Quando dizeré faz̨er: palavras e ação. Porto Alegre: Artes Médicas, 1990. 136 p. Primeira edição de 1962.

BASTOS, L. C.; BIAR, L. A. Análise de narrativa e práticas de entendimento da vida social. DELTA, São Paulo, v. 31, n. especial, p. 97-126, 2015.

BAUMAN, R. Story, performance and event: contextual studies of oral narrative. Cambridge: CUP, 1986. 130 p. Doi: https://doi.org/10.1017/CBO9780511620935 BAUMAN, Z. Globalização: as consequências humanas. Rio de Janeiro: Zahar, 1999. $146 \mathrm{p}$. 
BLOMMAERT, J. Sociolinguistic scales. 2006. Disponível em: <https://www. academia.edu/6465214/WP37_Blommaert_2006._Sociolinguistic_scales> Acesso em: 22 mar. 2018.

BLOMMAERT, J. A sociolinguistics of globalization. Cambridge: Cambridge University Press, 2010. 209 p. Doi: https://doi.org/10.1017/CBO9780511845307

BLOMMAERT, J.; RAMPTON, B. Language and superdiversity: a position paper. London: Tilburg University and King's College, 2011. (Working Papers in Urban Language \& Literacies, 70)

BLOMMAERT, J.; DE FINA, A. Chronotopic identities: on the timespace organization of who we are. Tilburg: Tilburg University, 2015. (Tilburg Papers in Culture Studies, 153)

BLOMMAERT, J.; WESTINEN, E.; LEPPÄNEN, S. Further notes on sociolinguistic scales. Tilburg: Tilburg University, 2014. (Tilburg Papers in Culture Studies, 89)

BRAH, A. Cartografias de la diáspora: identidades en cuestión. Madri: Traficantes de Suenos/Mapas, [1996] 2011. 297 p.

BROWN, G.; YULE, G. Discourse analysis. Cambridge: Cambridge University Press, 1983. 302 p. Doi: https://doi.org/10.1017/CBO9780511805226

BUTLER, J. Excitable speech: a politics of the performative. New York: Routledge, 1997. $184 \mathrm{p}$.

BUTLER, J. Problemas de gênero: feminismo e subversão da identidade. Rio de Janeiro: Civilização Brasileira, [1990] 2003. 236 p.

CARR, E. S.; LEMPERT, M. Scale discourse and dimensions of social life. Oakland: University of California Press, 2016. 276 p. Doi: https://doi.org/10.1525/ luminos.15

CONNELLY, F. M.; CLANDININ, D. J. Pesquisa narrativa: experiência e história em pesquisa qualitativa. Uberlândia: Edufu, 2011. 250 p.

COSTA, H. O fascismo social explode em paises periféricos como o Brasil. 2017. Disponível em: <http://www.substantivoplural.com.br/uma-ditadura-de-novo-tipo-ofascismo-social/>. Acesso em: 31 ago. 2018.

DE FINA, A.; GEORGAKOPOULOU, A. Analyzing narrative: discourse and sociolinguistic perspectives. Cambridge: Cambridge University Press, 2012. 240 p. FABRÍCIO, B. F.; MOITA LOPES, L. P. "Does the picture below show a heterosexual couple or not?": reflexivity, entextualization, scales and intersectionalities in a gay man's blog. FABRÍCIO, B. F.; MOITA LOPES, L. P. Gender and language. No prelo. 
FONSECA, T. M. G. et al. Microfascismos em nós: práticas de exceção no contemporâneo. Psicologia Clínica, Rio de Janeiro, v. 20, n. 2, p. 31-45, 2008.

FOUCAULT, M. A ordem do discurso. 5. ed. São Paulo: Loyola, [1971] 1999. 79 p.

FOUCAULT, M. Microfísica do poder. Rio de Janeiro: Graal, [1979] 2010. 295 p.

FREEMAN, M. Why narrative is here to stay. A return to origins. In: HYVÄRINEN, M.; HATAVARA, M.; HYDEN, L.-C. (Org.). The travelling concepts of narrative. Amsterdam: John Benjamins, 2013. 311 p. Doi: https://doi.org/10.1075/ $\sin$.18.04fre

FREITAS, L. F. R. A pedagogia do gauchismo: uma análise a partir da diáspora gaúcha. 2006. 159f. Tese (Doutorado em Educação) - Programa de Pós-Graduação em Educação, Universidade Federal do Rio Grande do Sul, Porto Alegre, 2006.

FREITAS, L. F. R. A sala de aula como um espaço que constitui a identidade gaúcha. Educação \& Realidade, Porto Alegre, v. 32, n. 2, p. 49-61, jul./dez. 2007.

FREITAS, L. F. R. Posicionamentos interacionais em pequenas histórias contadas por um universitário migrante - performances de masculinidade heterossexual. Fórum Linguístico, Florianópolis, v. 14, n. 2, p. 2116-2127, abr./jun. 2017. Doi: https://doi.org/10.5007/1984-8412.2017v14n2p2116

FREITAS, L. F. R.; MOITA LOPES, L. P. "Sobre feminismo, sobre racismo, sobre xenofobia, sobre tudo" - desequilibrios narrativos em performances heterossexuais de um aluno migrante branco. Calidoscópio, São Leopoldo, v. 15, n. 2, p. 305-316, maio/ago. 2017.

GAL, S. Scale-making: comparison and perspective as ideological projects. In: CARR, E. S.; LEMPERT, M. (Org.). Scale: discourse and dimensions of social life. Oakland: University of California Press, 2016. p. 91-111

GEE, J. Situated language and learning: a critique of traditional schooling. New York: Routledge, 2004. 144 p.

GUBRIUM, J. F.; HOLSTEIN, J. A. From the individual interview to the interview society. In: GUBRIUM, J. F; HOLSTEIN, J. A. (Org.). Postmodern interviewing. London: Sage, 2003. p. 21-49. Doi: https://doi.org/10.4135/9781412985437.n2

GUMPERZ, J. Convenções de contextualização. In: RIBEIRO, B. T.; GARCEZ, P. M. Sociolinguistica interacional. São Paulo: Loyola, [1982] 2002. p. 149-182.

HAESBAERT, R. $O$ mito da desterritorialização: do "fim dos territórios" à "multiterritorialidade". Rio de Janeiro: Bertrand Brasil, 2004. 396 p.

HARDT, M.; NEGRI, A. Multidão: guerra e democracia na era do império. Rio de Janeiro: Record, 2005. 532 p. 
IRVINE, J. T. Going upscale: scales and scale-climbing as ideological projects. In: CARR, E. S.; LEMPERT, M. Scale: discourse and dimensions of social life. Oakland: University of California Press, 2016. p. 213-231.

JACQUEMET, M. Transidiomatic practices: language and power in the age of globalization. Language \& Communication, Amsterdam, n. 25, p. 257-277, 2005.

KELL, C. Ariadne's thread: literacy, scale and meaning making across space and time. Tilburg: Tilburg University, 2013. (Tilburg Papers in Cultural Studies, 81)

KIM, J-H. Understanding narrative inquiry. Washington, DC: Sage, 2016. 341 p.

MELO, G. C. V.; MOITA LOPES, L. P. Ordens de indexicalidade mobilizadas nas performances discursivas de um garoto de programa: ser negro e homoerótico. Linguagem em (Dis)curso, Tubarão, v. 14, n. 3, p. 653-673, set./dez. 2014.

MELO, G. C. V.; MOITA LOPES, L. P. "Você é uma morena muito bonita": A trajetória textual de um elogio que fere. Trabalhos em Linguística Aplicada, Campinas, v. 54, n. 1, p. 53-78, jan./jul. 2015. Doi: https://doi.org/10.1590/010318134345161352

MENDES, J. M. Fascismo social. 2013. Disponível em: < https://www.ces.uc.pt/ observatorios $/$ crisalt $/$ index.php?id $=6522 \& i d \_l i n g u a=1 \& p a g=7738>$. Acesso em: 31 out. 2018.

MOITA LOPES, L. P. Por uma linguística aplicada indisciplinar. São Paulo: Parábola, 2006. 279 p.

MOITA LOPES, L. P. A performance narrativa do jogador Ronaldo como fenômeno no esporte e no sexo em um jornal carioca: multimodalidade, posicionamento e iconicidade. Revista da Anpoll, [s.l.], v. 27, p. 129-157, 2009.

MOITA LOPES, L. P. (Org.) O português no século XXI: cenário geopolítico e sociolinguístico. São Paulo: Parábola, 2013. 398 p.

MOITA LOPES, L. P. Global Portuguese: linguistic ideologies in late modernity. New York: Routledge, [2015] 2018. 235 p.

NAIL, T. The figure of the migrant. Stanford: Stanford University Press, 2015. 295 p.

PENNYCOOK, A. Global Englishes and transcultural flows. New York: Routledge, 2007. 189 p.

PETERSON, E. E.; LANGELLIER, K. M. The performance turn in narrative studies. Narrative Inquiry, Thousand Oaks, v. 16, n. 1, p. 173-180, 2006. Doi: https:// doi.org/10.1075/ni.16.1.22pet 
PHILIPS, S. U. Algumas fontes de variabilidade cultural na ordenação da fala. In: RIBEIRO, B. T.; GARCEZ, P. M. (Org.). Sociolinguística interacional. São Paulo: Loyola, [1976] 2002. p. 21-43.

RAMPTON, B. Language in late modernity: interaction in an urban school. Cambridge: Cambridge University Press, 2006. 443 p. Doi: https://doi.org/10.1017/ CBO9780511486722

SAFATLE, V. Um fascista mora ao lado. 2017. Disponível em: < http:/ /www1.folha. uol.com.br/colunas/vladimirsafatle/2017/03/1863080-um-fascista-mora-ao-lado. shtml>. Acesso em: 23 abril 2018.

SANTOS, B. S. A difícil reinvenção da democracia frente ao fascismo social. 2016. Disponível em: <http://www.ihu.unisinos.br/159-noticias/entrevistas/563035>. Entrevista concedida a Ricardo Machado. Acesso em: 31 ago. 2018.

SANTOS, M. Por uma outra globalização. Rio de Janeiro: Record, 2000. 174 p.

SILVA, D. N. Pragmática da violência: o Nordeste na mídia brasileira. Rio de Janeiro: 7Letras, 2012. 163 p.

SILVERSTEIN, M. Indexical order and the dialectics of sociolinguistic life. Language \& Communication, Amsterdam, v. 23, p. 193-229, 2003. Doi: https:/ /doi. org/10.1016/S0271-5309(03)00013-2

SILVERSTEIN, M. Pragmatic indexing. In: MEY, J. L. Concise encyclopedia of pragmatics. London: Elsevier, 2009. p. 756-759.

SQUIRE, C. et al. What is narrative research? London: Bloomsbury, 2014. 153 p.

VERTOVEC, S. Superdiversity and its implications. Ethnic and Racial Studies, Abingdon, v. 30, n. 6, p. 1024-1054, nov. 2007. Doi: https://doi. org/10.1080/01419870701599465

WESTMORELAND, M. et al. A roundtable on: Thomas Nail. The figure of the migrant. PhoenEx, [s.l.], v. 11, n. 1, p. 141-162, Spring/Summer 2016.

WORTHAM, S. Narratives in action. New York: Teacher's College Press, 2001. 183 p.

Data de submissão: 02/06/2018. Data de aprovação: 26/09/2018. 